Original Scientific Article

\title{
COMPARATIVE ANATOMICAL STUDIES ON DUCTUS VENOSUS IN FETUSES OF DOMESTIC RUMINANTS
}

\author{
Pamela Bejdić1, Amel Ćutuk ${ }^{2}$, Amer Alić3 , Benjamin Čengić ${ }^{4}$, Rizah Avdić1, \\ Faruk Tandir ${ }^{1}$, Nedžad Hadžiomerović ${ }^{1}$, Verica Mrvićs \\ ${ }^{1}$ Department of Anatomy and Histology with Embryology, Veterinary Faculty, \\ University of Sarajevo, Bosnia and Herzegovina \\ ${ }^{2}$ Department of Ambulatory Clinics, Veterinary Faculty, University of Sarajevo, \\ Bosnia and Herzegovina \\ ${ }^{3}$ Department of Pathology, Veterinary Faculty, University of Sarajevo, \\ Bosnia and Herzegovina \\ ${ }^{4}$ Department for Obstetrics and Udder Diseases, Veterinary Faculty, \\ University of Sarajevo, Bosnia and Herzegovina \\ ${ }^{5}$ Department of Anatomy, Faculty of Veterinary Medicine, University of Belgrade, Serbia
}

Received 18 March 2020; Received in revised form 7 October 2020; Accepted 9 November 2020

\begin{abstract}
The study has aimed to investigate and determine the anatomical position, shape, size, and histological features of the ductus venosus, and its role as a shunt in the fetal circulatory system in domestic ruminants. The research was conducted on 19 bovine, 11 sheep and 5 goat fetuses, aborted at the late stage of pregnancy or deceased just after delivery. The general anatomy of the ductus venosus was investigated by in-situ dissection of the corrosive cast obtained by injection of $25 \%$ solution of Vinylite mass through the umbilical vein. For histological examination, the fetal tissue samples were stained with Hematoxylin and Eosin, Masson's trichrome, Verhoeff-Van Gieson and Gomori's silver stain. The results showed that ruminant fetal ductus venosus is a curved, trumpet-shaped vessel, situated in the central part of the liver, above the porta hepatis. Its ventral part is constricted in the form of an isthmus, having a prominent lip-like thickening at the junction with the portal sinus. Histological examination showed the dominant presence of collagen and elastic fibers in its tunica media, with thin bands of smooth muscle fibers oriented in a longitudinal and circular direction indicating ability for vasoconstriction and vasodilatation.
\end{abstract}

Key words: umbilicus, ductus venosus, ruminants, anatomy, morphology

\section{INTRODUCTION}

Fetal circulation encompasses the blood flow through the placenta, umbilical cord, and the three physiological shunts: the ductus venosus (DV), foramen ovale and ductus arteriosus. The placenta and umbilical cord are a life-support connection for

Corresponding author: Dr. Pamela Bejdić, $\mathrm{PhD}$

E-mail address: pamela.bejdic@vfs.unsa.ba

Present address: Department of Anatomy and Histology with Embryology,

Veterinary Faculty, University of Sarajevo, Bosnia and Herzegovina Phone: +38761445886

Copyright: (C) 2020 Bejdić P. This is an open-access article published under the terms of the Creative Commons Attribution License which permits unrestricted use, distribution, and reproduction in any medium, provided the original author and source are credited.

Competing Interests: The authors have declared that no competing interests exist.

Available Online First: 14 December 2020

Published on: 15 March 2021

https://doi.org/10.2478/macvetrev-2020-0034 the fetus during the intrauterine life. The umbilical cord in humans, horses, donkeys and carnivores contains four structures: one umbilical vein, two arteries, and urachus, wrapped in mesenchymal connective tissue, also known as Wharton's jelly (1, $2,3,4)$. In pigs and domestic ruminants, including the camels and dromedaries, the umbilical cord contains five structures: two umbilical veins merging before entering the liver, two arteries, and urachus $(4,5,6)$. The umbilical vein emerges from the placenta and transports oxygenated and nutrientrich blood towards the fetal liver. Part of this blood bypasses the liver's parenchyma traversing through the DV, the caudal vena cava (CVC), foramen ovale, the left atria of the heart, and finally reaching the heart and brain. Numerous researches have 
attempted to explain the regulatory mechanism of the DV and its role as a shunt in the fetal blood circulation $(7,8,9,10,11,12,13,14,15)$. Recent studies conducted by conventional ultrasound and color Doppler imaging techniques revealed that the human fetal DV can shunt $25-40 \%$, whereas in animal fetuses about $50 \%$ of the total blood volume $(16,17,18)$. However, the mechanism of blood flow redistribution between umbilical vein, fetal liver, and the DV is still a matter of debate $(16,18,19)$. The studies indicate that the degree of shunting depends on numerous factors, including intrahepatic portal vasculature resistance, diameter and resistance of DV's wall, neural and endocrine regulation, blood viscosity, hypoxia, etc. (13, 15, 16). Additionally, the scientific literature has sparse information about the anatomical position, shape, size and histological features of DV in domestic ruminants. The research conducted in sheep, camels, and baboons' fetuses shows that the DV has an isthmic portion supplied with a ridge, lip, or horseshoe structure protruding into its lumen and acting as a sphincter $(5,10,20,21)$. Still, there is a controversial issue for the presence and the regulating mechanism of this sphincteric region in human and animal fetuses $(16,18)$. The use of ultrasound imaging techniques for monitoring and assessment of fetal well-being during pregnancy has a rising trend in veterinary medicine practice. The current study aimed to provide precise anatomical data about the position, shape, size, and histological features of the domestic ruminants' DV and its role as a shunt in the fetal circulatory system which will be useful in further clinical trials.

\section{MATERIAL AND METHODS}

The research was conducted on 19 bovine, 11 sheep and 5 goat fetuses. The bovine fetuses were obtained from a Holstein Friesian dairy cattle farm (Poljoprivredno dobro Butmir doo.). Fifteen fetuses were aborted at the late stage of the pregnancy prior the partus, and 4 died just after delivery. The small ruminant fetuses were obtained from individual farmers which bred native breeds of sheep (Dubska pramenka) and alpine goat. The fetuses were aborted just prior delivery and the necropsy was performed at the Department of Anatomy and Histology with Embryology, Veterinary Faculty, University of Sarajevo. The necropsy confirmed that the cause of death was not related to vascular or circulatory abnormalities nor due to drug-related maternal effect.
During the necropsy, the whole umbilical cord was carefully dissected and macroscopically observed. The umbilical vein was identified, its lumen washed with Ringer's solution and filled with $25 \%$ red colored Vinilyte solution. The injection was performed manually by using a plastic syringe. The pressure was applied until resistance appeared on the piston and until the umbilical vein and CVC were entirely filled. The CVC was ligated at both ends near the liver. Half an hour after the injections of Vinilyte mass we performed careful in-situ dissection of the umbilical vein, sinus portalis, and the DV. The position, shape, and size of the DV were noted.

Following the dissection, samples for histological examination were taken from the ventral, middle, and dorsal part of the DV, fixed in $10 \%$ buffered formalin solution, embedded in paraffin (Leica RM2145), and cut $(4-10 \mu \mathrm{m})$. The slides were stained with Hematoxylin and Eosin for routine histological examination, with Masson's trichrome for collagen fibers, with Verhoeff-Van Gieson for elastic fibers, and with Gomori's Silver Impregnation for reticular fibers (22). The slides were observed under light microscope (Olympus UC 30) with digital camera (Olympus UC 30).

After collecting the samples for histological examination, the fetuses were submerged in hydrochloric acid (33\%) for seven days, macerating soft tissues and obtaining the Vinylite casts. The casts were washed in tap water and observed under loupe for comparative analysis. Total (crown-rump) length of the DV was measured using digital caliper. The average values $(\mathrm{cm})$ for each ruminant species were estimated separately (Excel). The diameter of DV was not measured due to loss of volume in the Vinilyte cast following dehydration and hardening.

\section{RESULTS}

DV was identified as a long, slightly curved, trumpet-shaped vessel positioned centrally inside the liver in all fetuses. The duct traversed from porta hepatis to CVC, passing below the lobus caudatus and its processus papillares (Fig. 1). Its average length is presented in Table 1. The DV emerges from the dorsal part of the portal sinus which receives blood from the umbilical vein and intrahepatic branches of the portal vein. On the in-situ dissected casts, the umbilical vein entered the portal sinus from its ventral side, whereas DV emerged on its opposite dorsal side (Fig. 1). After separating from the portal sinus, the DV was directed in a dorsal and cranial direction continuing at a sharp angle 
into the CVC. Its opening was situated just above the orifice of the left hepatic vein (Fig. 2). The ventral part of the DV was constricted in a form of an isthmus which connects it to the portal sinus. At the junction of the DV and the portal sinus, a lip-like thickening was visible, protruding into its lumen without entirely occluding its diameter (Fig. 1). This lip-like structure was always attached to the right wall of the DV, while the left side of its lumen was always passable.

Table 1. The average length $(\mathrm{cm})$ of the ductus venosus in domestic ruminants with standard deviation

\begin{tabular}{lccc}
\hline Animal & Number of specimens & $\begin{array}{c}\text { Mean length of ductus } \\
\text { venosus (cm) }\end{array}$ & $\begin{array}{c}\text { Standard deviation } \\
\text { (St. dev) }\end{array}$ \\
\hline Bovine fetuses & 19 & 3.91 & 0.18 \\
Sheep fetuses & 11 & 2.67 & 0.23 \\
Goat fetuses & 5 & 2.34 & 0.14 \\
\hline
\end{tabular}
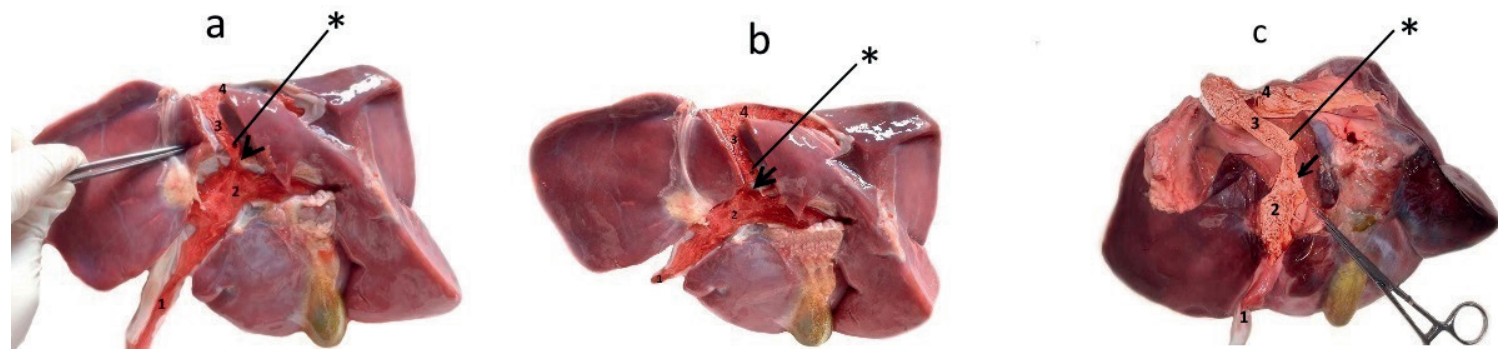

Figure 1. Cast and dissected in-situ intrahepatic blood vessels of bovine (a), sheep (b), and goat (c) fetus. In all specimens the following structures are visible: umbilical vein (1) continuing into the sinus portalis (2) from which protrudes the ductus venosus (3) directed dorsally and cranially continuing into the v. cava caudalis (4) at a sharp angle. At the junction of the ductus venosus and sinus portalis, on the right side, a thick, asymmetrical lip-like structure is visible protruding into the lumen (arrow). Above this structure, a retained Vinylite mass is visible $\left(^{*}\right)$

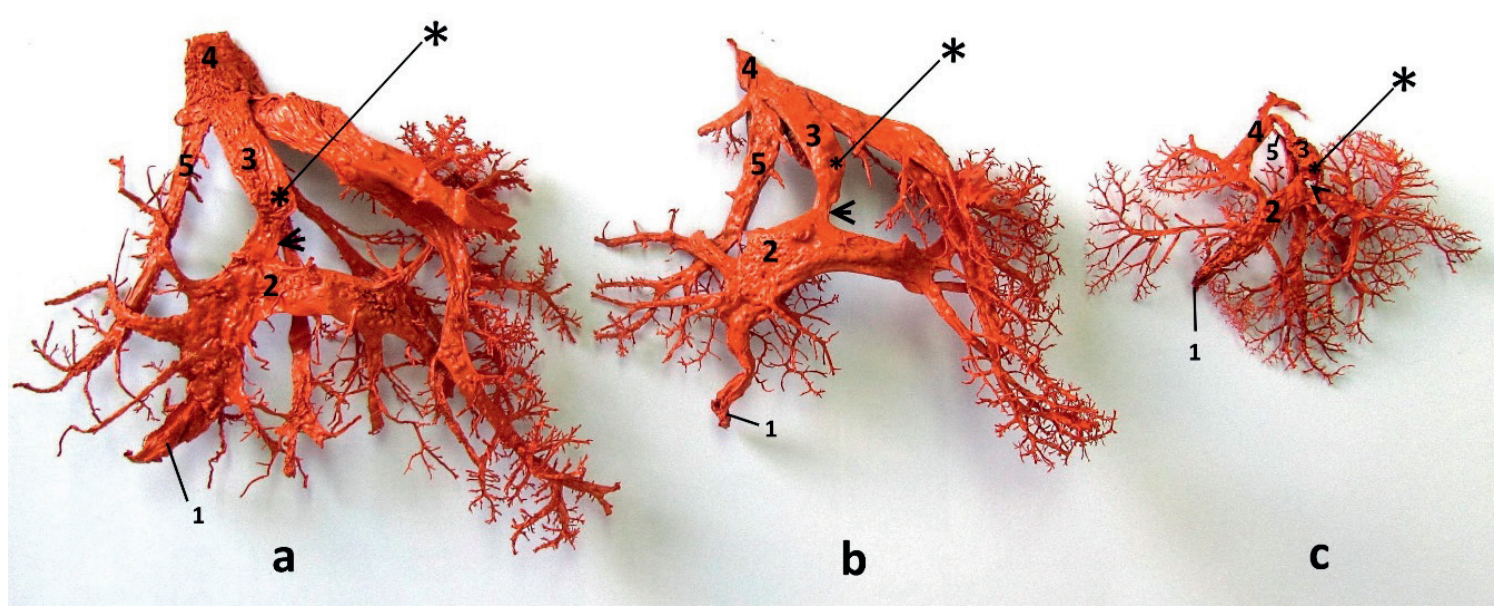

Figure 2. On the corrosive casts of the main intrahepatic blood vessels in bovine (a), sheep (b), and goat (c) fetuses the following structures are visible: umbilical vein (1), portal sinus (2), ductus venosus (3) and v. cava caudalis (4). The ductus venosus inflows into the v.cava caudalis at a sharp angle and its orifice is situated above the orifice of the left hepatic vein (5). The ventral part of the duct is constructed in a form of an isthmus (arrow), above which a retained Vinylite mass $(*)$ is visible on its right side 
Dissection showed that this structure acts as a valvular shunt. It retained the injected Vinilyte mass, especially on the right side of the isthmic portion above the lip-like thickening (Fig. 1 and Fig. 2). Also, during dissection, we noticed that the wall of the DV was thinner and paler than any other intrahepatic blood vessel.

Histological examination showed that the DV had a typical structure for a blood vessel. Tunica intima, media, and externa (adventitia) were identified (Fig. 3a). Tunica intima consisted of one layer of flattened endothelial cells. The internal elastic lamina situated beneath it was thin and discontinuous. It contained collagen, thin elastic, and reticular fibers interlaced with individual smooth muscle fibers (Fig. 3b, 4a and 5a). Tunica media was the thickest layer mainly composed of collagen (Fig. 3b), elastic (Fig. 4a, b), and reticular fibers (Fig. 5a, b). The collagen and elastic fibers were oriented in a longitudinal direction, while the reticular fibers were organized in a mesh. This structural organization was interlaced by smooth muscular bundles organized in longitudinal and circular layers. The longitudinal muscular layer was situated superficially, next to the lumen, while the circular was deeper, positioned along the adventitia (Fig. 3a, b). They were both composed of two to four layers of smooth muscular fibers. The external

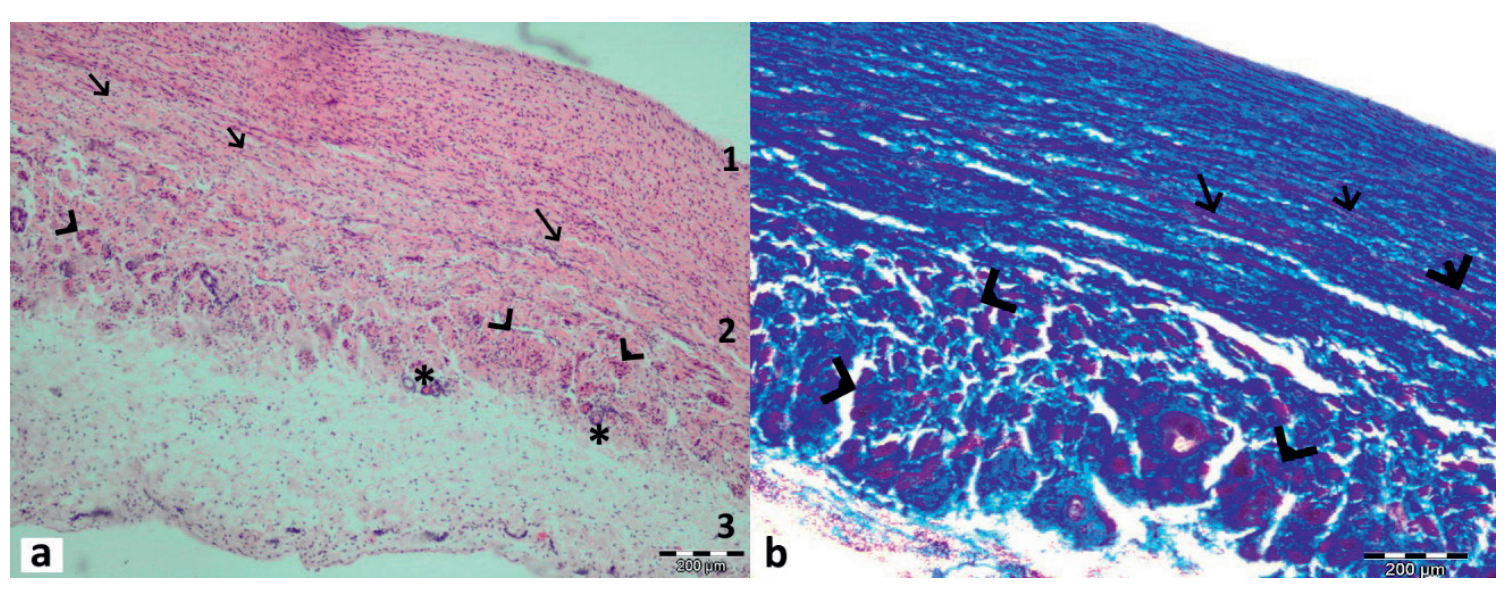

Figure 3. Longitudinal section through the middle part of the ductus venosus in bovine fetus stained with Hematoxylin and Eosin (a) and in sheep fetus stained with Masson's trichrome (b). All three layers are visible in this section: tunica intima (1) with thin endothelium and internal elastic lamina, tunica media (2) with an abundant amount of collagen (blue-stained) fibers, and longitudinal (arrow) and circular muscular bundles (arrowhead) between them. Tunica externa is the outermost layer (3) with visible blood vessels (*)

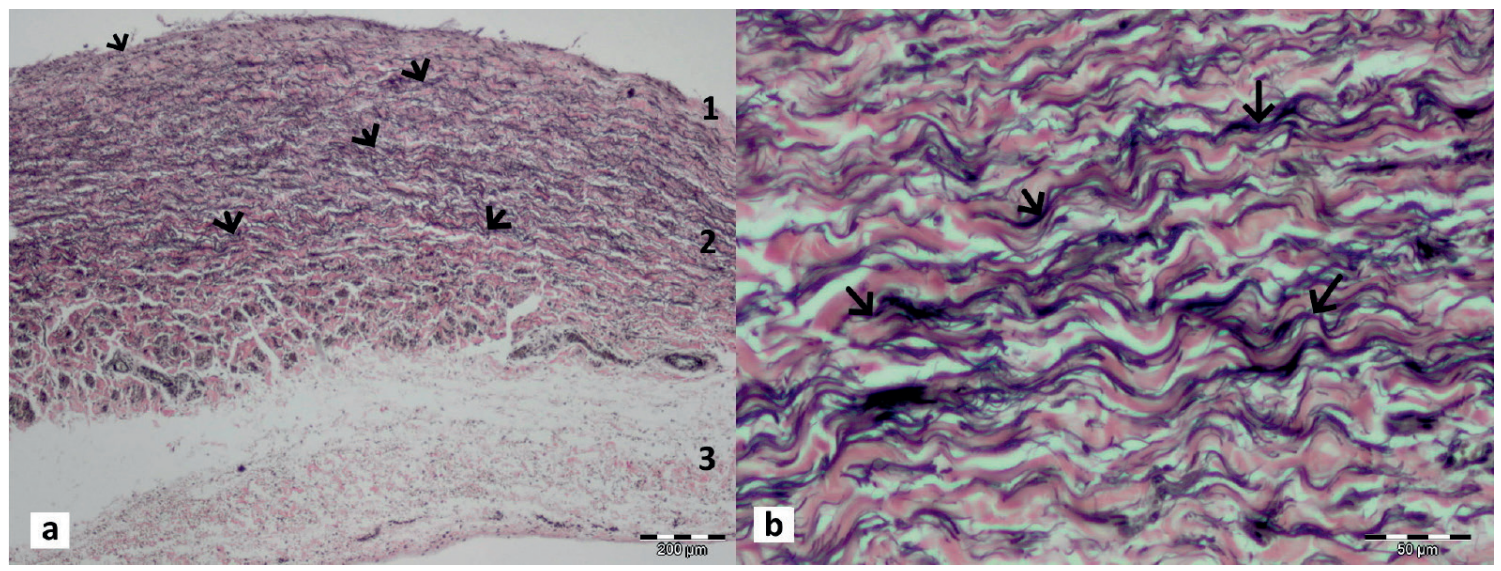

Figure 4. Longitudinal section through the middle part of the ductus venosus in bovine (a) and goat fetus (b) stained with Verhoeff-Van Gieson stain. In tunica media (2) numerous elastic fibers (arrows) are visible, stained in black. Some of these are present in tunica intima (1) and adventitia (3) 


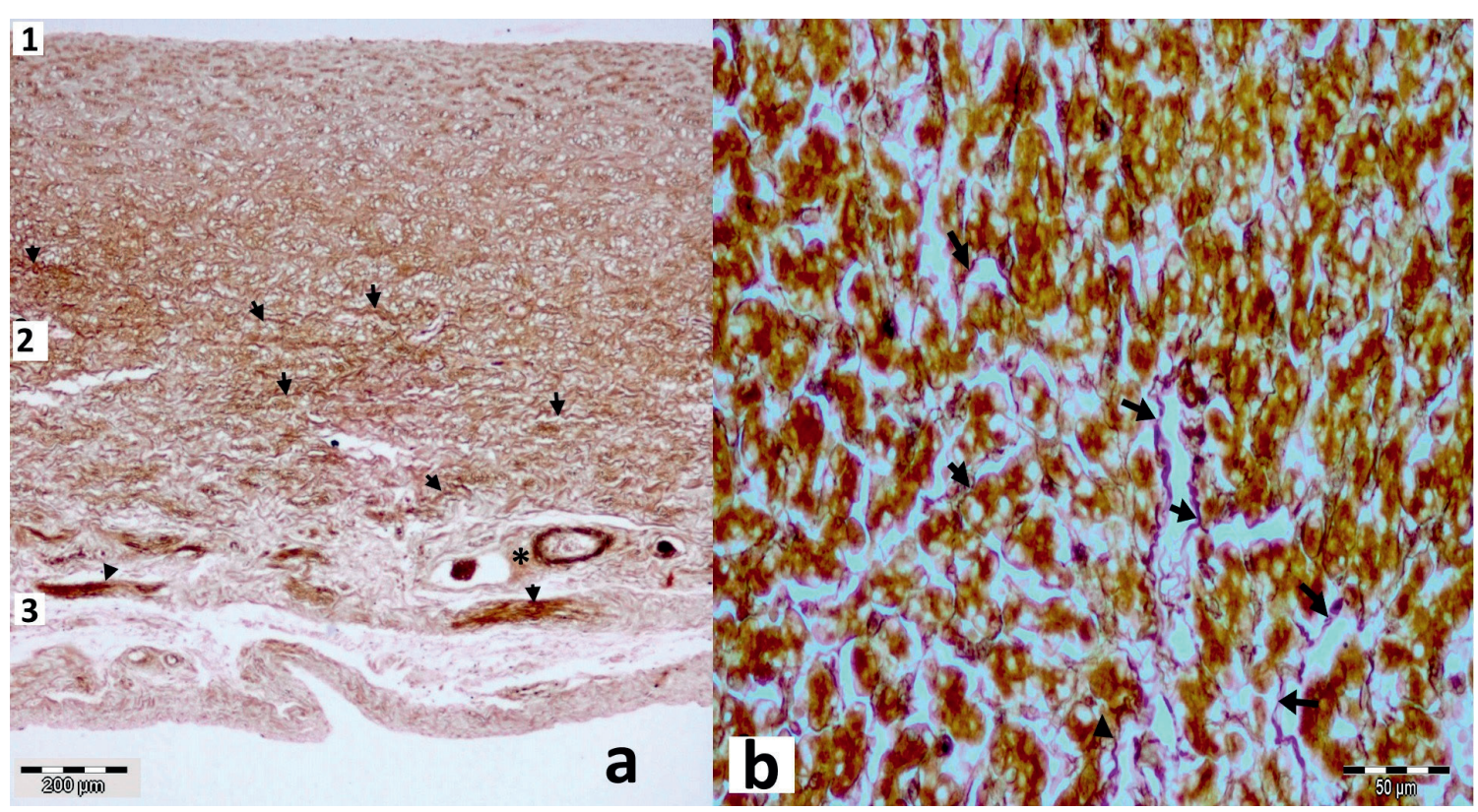

Figure 5. Longitudinal section through the middle part of bovine (a) and sheep ductus venosus (b) stained with Gomori's Silver impregnation technique. Dark-stained reticulin fibers (arrows) are visible in tunica media (2), distributed in a mesh-like form. Some of these fibers are present in tunica intima (1) and adventitia (3) including some blood vessels $(*)$

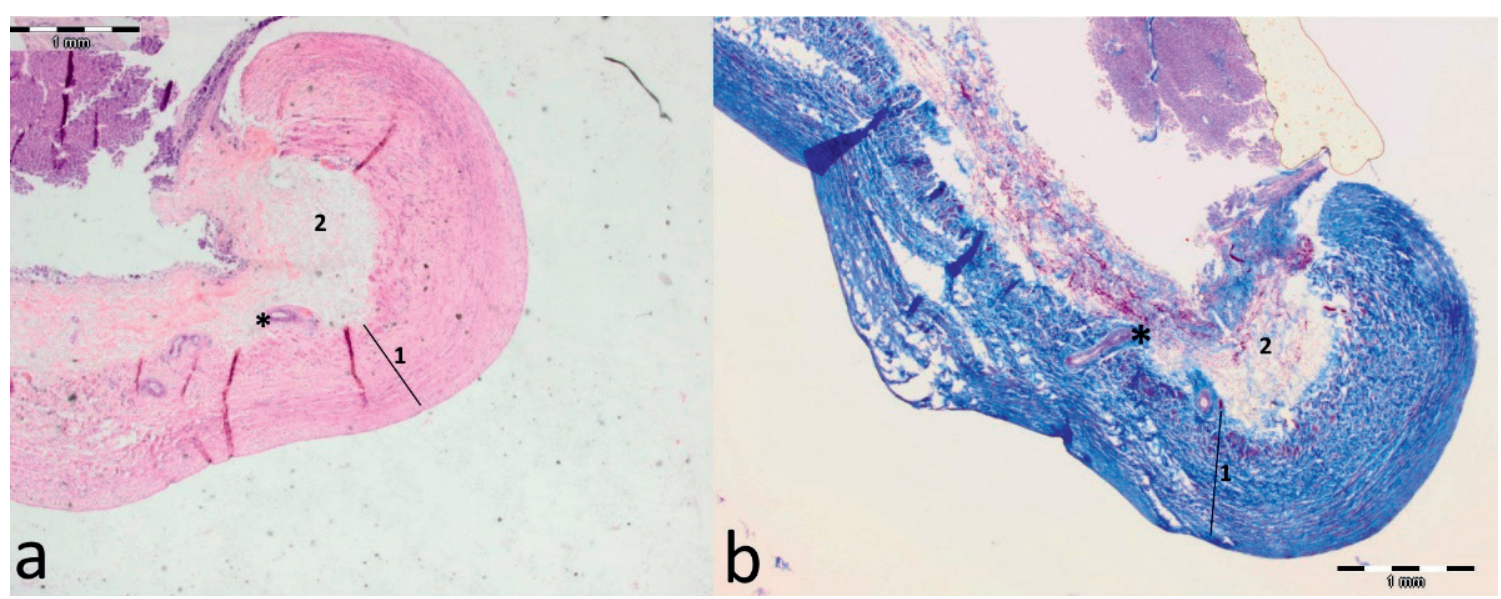

Figure 6. Longitudinal sections through the isthmic portion of the ductus venosus and its lip-like thickening in bovine fetus stained with Hematoxylin and Eosin (a) and in goat fetus (b) stained with Masson's trichrome stain (b). It is visible that tunica media (1) and adventitia (2) are much thicker in this lip-like area than the rest part of the ductus venosus. Both layers in this area contain a higher amount of collagen and elastin fibers. The tunica media has more longitudinal and circular smooth muscle layers. Vasa vasorum $\left(^{*}\right)$ are present at the base of this thickening

elastic lamina was wide and rich in collagen (Fig. 3b) and elastic fibers (Fig. 4b). The outermost layer (adventitia) contained lower amounts of collagen, elastic and reticular fibers than the previous layer. Numerous blood vessels (vasa vasorum) and nerve fibers were identified in this layer (Fig. 3a, 5a and 6a). These histological characteristics were recognized along the entire length of the DV, including its isthmic part. The tunica media and adventitia were much thicker in the area of the lip-like thickening than any other part of the DV (Fig. 6a, b). The endothelium and internal elastic lamina 
had the characteristic structure as in the other parts of the DV. The adventitia contained a higher amount of collagen and elastic fibers with the presence of smooth muscle fibers, blood vessels, and nerves (Fig. 6a, b). The tunica media was mainly built of longitudinal and circular smooth muscle layers with a significant amount of collagen, elastic, and reticular fibers. In general, this sphincteric region contained more collagen and elastic, then muscular fibers.

\section{DISCUSSION}

A considerable number of studies have attempted to explain the functional anatomy of the DV in the fetal circulatory system $(16,18)$. The earliest studies were based on post-mortem examinations. Later, various experimental and clinical methods have been implemented. The recent research methodology uses conventional and color Doppler ultrasound $(7,8,11,13,21)$. The main aim of these studies was to determine the mechanism of blood flow redistribution between the umbilical and intrahepatic vein, and the DV and CVC. However, there is still very limited anatomical information about the DV in domestic ruminants.

The corroded and in-situ dissected specimens in this study provided detailed and accurate information about the position and shape of this anatomical structure. This data can be used for ultrasound or another type of clinical examination for these animal species. Similar position and shape of DV was also found in camel fetuses (4). However, the authors have described the DV as a simple vessel connecting the umbilical vein and the CVC. They have not mentioned the isthmic portion or presence of any structure at its junction with the portal sinus. The histological description in the current study is in agreement with reported description of the DV in camel fetuses (5). The liplike or horseshoe structure in the isthmic portion of the DV with a ridge protruding in its lumen acting as a sphincter has been described in sheep fetuses $(20,21)$. The current investigation confirms the presence of this structure not only in sheep but also in all other ruminant fetuses. Furthermore, the current study has identified a thick, asymmetrical, lip-like structure on the right wall of the isthmic portion, at the point where it connects with the portal sinus. This was noticeable by the retained Vinylite mass, especially on the right side of the lumen, whereas the left was still passable. These findings indicated that the structure has an impact on the redistribution of intrahepatic blood flow in ruminant fetuses and should be considered during the ultrasound assessment. Ultrasound studies in sheep fetuses reveal presence of a membranous valve on the communication between the $\mathrm{DV}$, left hepatic vein, and CVC redirecting the blood flow towards the foramen ovale $(11,13,15)$. The current study has not identified such a structure, but it was acknowledged that the DV enters into the CVC at a sharp angle and its orifice is situated just above the orifice of the left hepatic vein. Regarding histological features, the DV has been described as an organized vascular structure in sheep, goat, camel, mice, rats, dogs, cats, primates, and human fetuses $(6,10,21)$.

Light and electron microscopic investigation showed that the DV in sheep fetuses has an extra-sphincteric and sphincteric region $(10,21)$. Endothelial cells are lining the luminal surface of both regions $(10,21)$. The extra-sphincteric region was composed of connective tissue containing fibroblasts, collagen, elastin, and a few strands of smooth muscle cells, while the sphincteric region was thicker and contained one or two additional layers of smooth muscle cells. The outer adventitia layer was mostly composed of collagen fibers interspersed with fibroblasts and a few myofibroblasts $(10,21)$. The current investigation partially agrees with these statements. All three layers of the DV were identified in the current research. However, in addition to the abundant amount of collagen and elastic fibers in tunica media, smooth muscular bundles organized in longitudinal and circular layers were identified along the entire length of the DV. Muscular bands in tunica media were with higher density and organization in the lip-like region which concurs with the previously cited reports. Additionally, it was noted that the adventitia had a higher thickness and density of collagen and elastic fibers.

\section{CONCLUSION}

The present study gives an accurate anatomical description of the position, shape, and size of the DV in domestic ruminant fetuses. The current findings could be useful guidelines for dissection, ultrasound imaging or other types of examinations.

The position, the curved trumped-shape form of the DV, and the lip-like thickening of its isthmic part at the junction with the portal sinus may have an impact on intrahepatic blood flow distribution. 
This potential role should be considered during the assessment of fetal intrahepatic circulation in domestic ruminants.

The presence of longitudinal and circular smooth muscular bundles in tunica media, indicates that the DV can contract along its entire length. Due to the high density of collagen and elastic fibers, this vessel can potentially exert both vasoconstriction and vasodilatation ability.

\section{CONFLICT OF INTEREST}

The authors declared that they have no potential conflict of interest with respect to the authorship and/or publication of this article.

\section{ACKNOWLEDGEMENTS}

The authors would like to express their gratitude to Jovana Šupić, DVM from the Department of Pathology, Veterinary Faculty, the University of Sarajevo for excellent laboratory assistance.

\section{AUTHORS' CONTRIBUTIONS}

PB proposed the study design, participated in necropsy, corrosive cast, and histopathology methodology, and writing the manuscript. AĆ and BC were involved in field work, necropsy, data gathering and statistical analysis. AA performed histopathology and results data interpretation. RA was involved in literature review, data analysis and interpretation. FT and NH were involved in necropsy, corrosive casts methodology, and data interpretations. VM did the critical revision of the manuscript and adaptation to the journal. All authors contributed to the final version of the manuscript.

\section{REFERENCES}

1. McGrady, T.A., Quinn, P.J., FitzPatrick, E.S., Ryan, M.T. (2006). Veterinary embryology. In: Cardiovascular system (pp. 105-130). Oxford, UK: Blackwell Publishing Ltd.

2. Hyttel, P., Sinowatz, F., Vejlsted, M., Betteridge, K. (2010). Essentials of domestic animal embryology. In: Poul Hyttel (Ed.), Development of the blood cells, heart and vascular system (pp. 198-207). Edinburgh, London, New York, Oxford, Philadelphia, St. Louis, Sydney, Toronto: Elsevier Limited.
3. Arpi, L.M.B. (2018). Histology. Histology of umbilical cord in mammals. [Internet]. (pp 47-58). IntechOpen. Open Access Peer-Reviewed Edited Volume. Provisional Chapter. [Available from: http://dx.doi.org/10.5772/intechopen.80766] https://doi.org/10.5772/intechopen.80766 PMid:31123483 PMCid:PMC6511591

4. Shaker, N.A., El Gammal, S.M. (2018). Comparative anatomical studies on the fetal remnants in donkey (Asinus Equus) and camel (Camelus Dromedarius). IOSR-JAVS. 11(5): 12-21.

5. Elgozouli, S.O., Osman, D.I. (2012). Histology of the constituents of the umbilical cord and ductus arteriosus and ductus venosus of the dromedary camel. JVA. 2(9): 449-456.

6. Igbokwe, C.O., Muokwah, E.C., Ezeasor, D.N. (2015). Developmental changes in the morphology of some blood vessels in the foetuses of the red sokoto goat. J Anim Plant Sci. 25(3): 625-632.

7. Botti, J.J., Edelstone, D.I., Caritis, S.N., MuellerHeubach, E. (1982). Portal venous blood flow distribution to liver and ductus venosus in newborn lambs. Am J Obstet Gynecol. 144(3): 303-308. https://doi.org/10.1016/0002-9378(82)90583-X

8. Edelstone, D.I., Rudolph, A.M., Heymann, M.A. (1978). Liver and ductus venosus blood flows in fetal lambs in utero. Circ Res. 42(3):426-433.

9. Zink, J., Van Petten, G.R. (1980). Time course of closure of the ductus venosus in the newborn lamb. Pediatr Res. 14(1): 1-3. https://doi.org/10.1203/00006450-198001000-00001 PMid:7360516

10. Coceani, F., Adeagbo, A.S., Cutz, E., Olley, P.M. (1984). Autonomic mechanisms in the ductus venosus of the lamb. Am J Physiol (Heart Circ Physiol). 247(1): H17-H24.

https://doi.org/10.1152/ajpheart.1984.247.1.H17 PMid:6742210

11. Rudolph, A.M. (1985). Distribution and regulation of blood flow in the fetal and neonatal lamb. Brief review. Circ Res. 57(6): 811-821.

https://doi.org/10.1161/01.RES.57.6.811

PMid:3905044

12. Rudolph, A.M. (1983). Hepatic and ductus venosus blood flows during fetal life. Hepatology 3(2): 254-258. https://doi.org/10.1002/hep.1840030220 PMid:6832717

13. Kiserud, T., Eik-Nes, S.H., Blaas, H.G., Hellevik, L.R. (1991). Ultrasonographic velocimetry of the fetal ductus venosus. Lancet 338(8780): 1412-1414. https://doi.org/10.1016/0140-6736(91)92720-M 
14. Rudolph, C.D., Meyers, R.L., Paulick, R.P., Rudolph, A.M. (1991). Effects of ductus venosus obstruction on liver and regional blood flows in the fetal lamb. Pediatr Res. 29(4): 347-352.

https://doi.org/10.1203/00006450-199104000-00004 PMid:1852527

15. Schmidt, K.G., Silverman, N.H., Rudolph, A.M. (1996). Assessment of flow events at the ductus venosus - inferior vena cava junction and at the foramen ovale in fetal sheep by the use of multimodal ultrasound. Circulation 93(4): 826-833.

https://doi.org/10.1161/01.CIR.93.4.826

PMid:8641013

16. Kiserud, T. (1999). Hemodynamics of the ductus venosus. EJOG. 84(2): 139-147. https://doi.org/10.1016/S0301-2115(98)00323-6

17. Kiserud, T., Acharya, G. (2004). The fetal circulation. Prenat Diagn. 24(13): 1049-1059.

https://doi.org/10.1002/pd.1062

PMid:15614842

18. Tchirikov, M., Schröder, H.J., Hecher, K. (2006). Ductus venosus shunting in the fetal venous circulation: Regulatory mechanisms, diagnostic methods and medical importance. Ultrasound Obstet Gynecol. 27(4): 452-461.

https://doi.org/10.1002/uog.2747

PMid:16565980
19. Kiserud, T. (1997). In a different vein: the ductus venosus could yield much valuable information. Ultrasound Obstet Gynecol. 9, 369-372. https://doi.org/10.1046/j.1469-0705.1997.09060369.x PMid:9239820

20. Tchirikov, M., Schlabritz-Loutsevitch, N.E., Hubbard, G.B., Schröder, H.J., Nathanielsz, P.W. (2005). Structural evidence for mechanisms to redistribute hepatic and ductus venosus blood flows in nonhuman primate fetuses. AJOG. 192(4): 1146-1152.

21. Adeagbo, A.S.O., Kelsey, L., Coceani, F. (2004). Endothelin-induced constriction of the ductus venosus in fetal sheep: Developmental aspects and possible interaction with vasodilatory prostaglandin. Br J Pharmacol. 142(4): 727-736.

https://doi.org/10.1038/sj.bjp.0705849

PMid:15172962 PMCid:PMC1575056

22. Bancroft, J.D., Layton, C. (2019). Connective and other mesenchymal tissues with their stains. In: Suvarna S.K., Bancroft, J.D. (Eds.), Bancroft's theory and practice of histological techniques (pp. 53-175). Printed in China: Elsevier Limited.

Please cite this article as: Bejdić P., Ćutuk A., Alić A., Čengić B., Avdić R., Tandir F., Hadžiomerović N., Mrvić V. Comparative anatomical studies on ductus venosus in fetuses of domestic ruminants. Mac Vet Rev 2021; 44 (1): $29-36$. https://doi.org/10.2478/macvetrev-2021-0034 